\title{
Effects of tooth profile and belt speed on cogged V-belt vibration and stress
}

\author{
Zechen Zeng, Xianglong Zhang, Jiangming Kan and Wenbin Li \\ School of Technology, Beijing Forestry University, Beijing 100083, China
}

\begin{abstract}
With the aim of reducing the vibration and maximum stress of a cogged V-belt and determining the appropriate cogged V-belt for the vertical disc stump grinder (RG25HD), this paper analyses the relationship between, on the one hand, the horizontal displacement of the vibration and node stress and, on the other, the tooth profile and belt speed. In addition, the pattern of the vibration and node stress of the cogged V-belt is investigated using various tooth profiles and belt speeds. Our approach uses a rigid/flexible coupling simulation of belt power transmission based on a finite element flexible body method and employs Recurdyn multi-body dynamics software. After the simulation, we obtain the stress distribution of the belt, the lateral displacement curve and the node stress curve. Our results indicate that cog shape affects belt stress and vibration. When selecting or designing a cogged V-belt, a belt with trapezoidal $\operatorname{cogs}$ is preferable. Regarding the effect of belt speed, the trapezoidal cogged V-belt's lateral vibrating displacement and maximal stress increase with an increase in belt speed. Therefore, when the stump grinder is in operation, its revolving speed should be maintained at a low rate to reduce vibration and prolong the belt's life.
\end{abstract}

\section{Introduction}

Most Chinese fast-grown, high-yield forests have entered a mature or over-mature period. Forests that have many cutting roots must be maintained after rotation, and tree stumps must be cleared during landscaping. The vertical disc stump grinder, a light-duty machine used to remove stumps and build caves, has been extensively employed. The machine can not only cut stumps to increase soil fertility but also creates a deep hole to facilitate reforestation and subsequent production. The RG25HDtype vertical disc stump grinder (RAYCO; Wooster, OH 44691, USA) transmits power to the cutting element by a cogged V-belt. However, the cogged V-belt vibrates considerably when the machine is at work, which has a substantial impact on the belt fender and leaves a black mark (figure 1). A cogged V-belt has better flexibility and heat dissipation performance [1] than an ordinary $\mathrm{V}$ belt. Tooth form and belt speed affect the vibration and stress of the belt, thus affecting the belt's transmission stability and service life. However, the GB does not specify the tooth form of the cogged V-belt. In the literature, most studies have been performed on synchronous, flat or multi-wedge belts. Several scholars have studied the dynamic performance of synchronous belts with different tooth forms and the transmission optimization of a synchronous belt [2-6] and obtained the vibration and stress distribution of such a belt for various tooth forms. A number of researchers have performed transmission simulations of the ordinary V-belt, flat belt and multi-wedge belt [7-9]. Although the various experts use different research methods [10-12], the most commonly used approach is rigid flexible coupling simulation based on a modal flexible body $[13,14]$. In the study of the influence of the tooth form on belt transmission characteristics, the belt undergoes greater displacement and deformation in the transmission process because of the large centre distance, which is more obvious under high-speed operation. Therefore, rigid flexible coupling simulation based on a modal flexible body confronts substantial limitations when describing the nonlinear behaviour of the belt, such as large deformations and contact [15].

With the development of the dynamics of rigid flexible coupled multibody systems and the gradual improvement in computer hardware, rigid flexible coupling simulation based on a finite element flexible body has become a useful tool for analysing belt transmission. This paper focuses on cogged V-belt power transmission and provides a basis for the selection and design optimization of a cogged $\mathrm{V}$-belt by rigid flexible coupling simulation with different tooth forms (i.e., trapezoidal, circular and triangular) at various speeds.

\section{Principle}

\subsection{Principle of finite element flexible body modeling}

Different from the method of using a modal flexible body to solve large degree of freedom systems, the finite 
element flexible body uses node displacement and node slope as nodal coordinates instead of the dynamic substructure modal synthesis method. In the modal synthesis method, the flexible body is typically viewed as a set of finite element model nodes, and the elasticity and deformation of the object are described by the model. The flexible body established by this method is more effective for systems with small elasticity and small deformation. Different from the modal flexible body, the deformation of a flexible body is described by the relative displacement and rotation between flexible body nodes. The absolute nodal coordinate equation is based on the geometric nonlinear theory of continuous structure. Because of the high-order term of the longitudinal strain and the elastic force, the absolute nodal coordinate equation can be used to analyse the large deformation of the structure. Considering the system dynamics, this method can accurately predict contact problems between flexible bodies and rigid bodies. Additionally, effective stress can be directly obtained by this method.

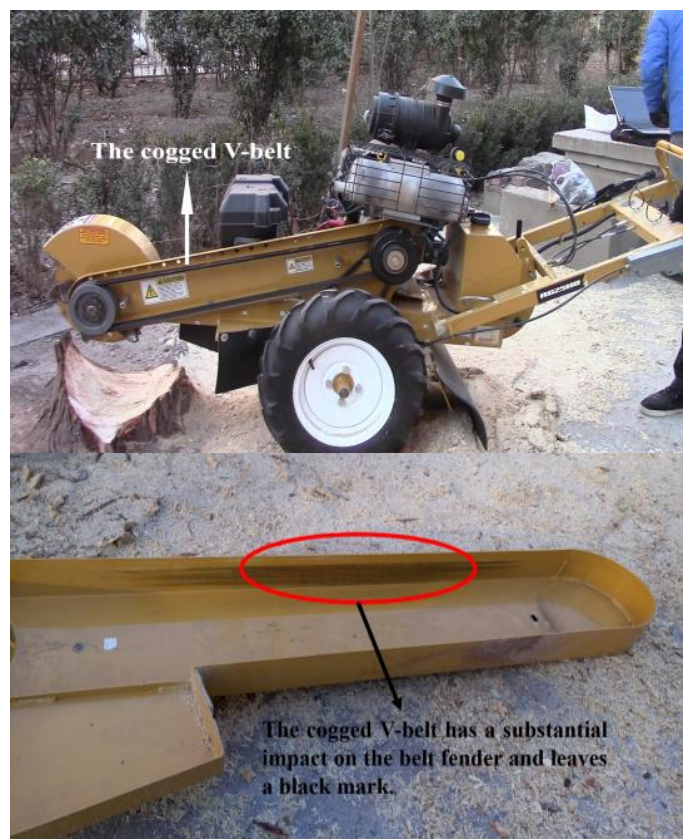

Figure 1. Cogged V-belt and shelter of stump grinder

\subsection{Influence of vibration and stress on belt transmission}

Practice shows that the failure modes of belt power transmission include skid, fatigue fracture and wear. Among them, skidding and fatigue fracture are the most common failure modes. Therefore, the design principle of belt transmission is to guarantee sufficient fatigue strength and service life with no skidding.

Since the belt is a large flexible component, it causes unexpected lateral vibration when it operates. Lateral vibration not only produces noise and accelerates belt wear but also causes belt removal and affects transmission accuracy. Therefore, it is reasonable to adopt vibration at the start of and during transmission as an evaluation criteria for the tooth form of the cogged $\mathrm{V}$ belt.
According to the design principle of belt transmission, the maximum stress of belt $\sigma_{\max } \leq \sigma_{r N}, \sigma_{r N}$ is the finite life fatigue limit, where the subscript mark $\boldsymbol{r}$ represents the stress ratio of the differential force and $\boldsymbol{n}$ represents the corresponding number of stress cycles. It can be experimentally observed that the maximum stress and the number of stress cycles have the following relations:

$$
\sigma_{r N}^{m} N=C
$$

In this equation: $\boldsymbol{\sigma}_{\boldsymbol{r}}$ is finite life fatigue limit, $\mathrm{MPa} ; \boldsymbol{m}$ is material constant, whose value is determined experimentally; $\boldsymbol{N}$ is stress cycle times; $\boldsymbol{C}$ is a constant. By equation (1), it is known that for a belt of definite material and structure, when $\boldsymbol{C}$ is the fixed value, the larger that the fatigue limit of finite life is, the smaller the stress cycle is, that is, the shorter the life of the belt. Therefore, the smaller that the limit of fatigue life of the designed tooth form of a cogged V-belt is (that is, the smaller the maximum stress), the better the tooth form is.

Comprehensive analysis shows smaller lateral vibration and maximum stress are beneficial to improving belt transmission stability and belt service life.

\section{Establishment of rigid flexible coupling model of cogged V-belt}

\subsection{Determination of belt and pulley parameters}

The "Mechanical design manual" and "GB/T 6931.32008" only describe the cogged V-belt in terms of structural features and applications and do not specify its teeth. Based on the RG25HD type vertical disc stump grinder, this paper designs three tooth forms for a cogged V-belt with reference to the synchronous toothed belt: trapezoidal, circular and triangular. The tooth form parameters of the cogged V-belt refer to the $\mathrm{L}$ type synchronous belt with trapezoidal teeth (table 1). The cross-sectional parameters of the cogged V-belt refer to the A type plain V-belt (table 2). The tape line is 1066.8 $\mathrm{mm}$, with a total of 112 teeth. The longitudinal section of each type cogged V-belt is shown in figure 2.

Table 1. The parameters of trapezoid tooth.

\begin{tabular}{cc}
\hline parameter & value \\
\hline Pitch & $9.525 \mathrm{~mm}$ \\
Tooth profile angle & $40^{\circ}$ \\
Tooth thickness & $4.65 \mathrm{~mm}$ \\
Tooth height & $1.91 \mathrm{~mm}$ \\
Fillet radius & $0.51 \mathrm{~mm}$ \\
Tip radius & $0.51 \mathrm{~mm}$ \\
\hline
\end{tabular}

Table 2. The parameters of cogged V-belt's cross section.

\begin{tabular}{cc}
\hline parameter & value \\
\hline Pitch width & $11 \mathrm{~mm}$ \\
Tip width & $13 \mathrm{~mm}$ \\
height & $8 \mathrm{~mm}$ \\
Wedge angle & $40^{\circ}$ \\
Applicable groove reference width & $11 \mathrm{~mm}$ \\
\hline
\end{tabular}

According to the type of cogged V-belt, the belt pulley also chooses the A-type V-belt pulley. The pulley's groove parameters are shown in table 3 . The datum width system is adopted in this paper. The reference diameter of 
the driving pulley $\boldsymbol{d}_{\boldsymbol{d}}$ is $112 \mathrm{~mm}$, and the reference diameter of the driven pulley is $150 \mathrm{~mm}$.

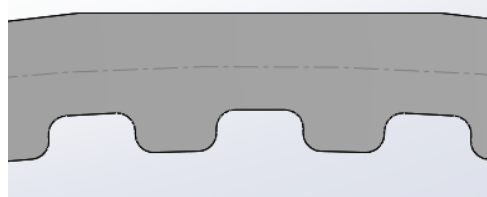

(a) Trapezoidal tooth

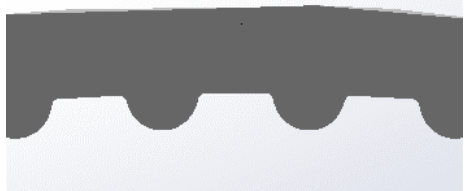

(b) Circular tooth

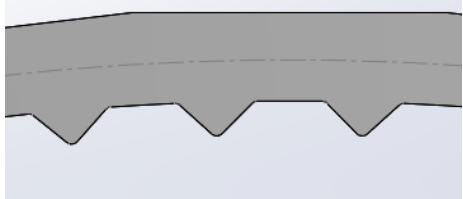

(c) Triangular tooth

Figure 2. Cross sections of three cogged V-belts.

Table 3. Parameters of the belt pulley's groove shape.

\begin{tabular}{cc}
\hline parameter & value \\
\hline $\boldsymbol{b}_{\boldsymbol{d}}$ & $11.0 \mathrm{~mm}$ \\
$\boldsymbol{h}_{\text {amin }}$ & $2.75 \mathrm{~mm}$ \\
$\boldsymbol{h}_{\text {fmin }}$ & $8.7 \mathrm{~mm}$ \\
$\boldsymbol{e}$ & $15 \pm 0.3 \mathrm{~mm}$ \\
$\boldsymbol{f}_{\text {min }}$ & $9 \mathrm{~mm}$ \\
$\boldsymbol{\delta}_{\text {min }}$ & $6 \mathrm{~mm}$ \\
$\boldsymbol{r}_{\boldsymbol{2}}$ & $0.5 \sim 1 \mathrm{~mm}$ \\
Wedge angle & $34^{\circ}$ \\
\hline
\end{tabular}

\subsection{Model import and mesh generation}

First, we import the pulleys and belts with the stp format into the Recurdyn software program. To speed up the process and make the flexible body easy to edit, we use the Mesher function to mesh the belt into a flexible body. The three cogged V-belts are selected with Solid4 units in the meshing process. Each Solid4 unit has 4 nodes, and each node has 3 degrees of freedom, which can be used for 3D solid body model. The modulus of elasticity is $2000 \mathrm{MPa}$, the density is $1.65 \times 10^{3} \mathrm{~kg} / \mathrm{m}^{3}$, and the Poisson's ratio is 0.47 . The pulley material is steel. The final meshing units and the number of nodes are shown in table 4.

Table 4. Number of nodes and elements for the three cog files.

\begin{tabular}{cccc}
\hline Type & trapezoidal & circular & triangular \\
\hline Nodes & 21958 & 31673 & 25323 \\
Elements & 80794 & 103304 & 92082 \\
\hline
\end{tabular}

\subsection{Drive and touch settings}

An initial tension is applied to the cogged V-belt with the cylinder as the transition part. We add a rotating pair between the cylinder and the driven pulley and a moving pair between the cylinder and the ground. Then, we add a revolute pair between the driving pulley and the reference coordinate system (i.e., the ground). Next, a start-up function for the driving pulley is executed via the step function. Finally, we establish the centre distance between the driving pulley and the driven pulley as 330 $\mathrm{mm}$.

In actual operation, the cogged V-belt transmits power by the friction between the side of the belt and the side of the pulley groove. Therefore, a contact constraint is required. The contact between the belt and the pulley is the contact between the flexible surface and the rigid surface. Therefore, the command Ssuf.ToFsuf is selected in the contact option under Flexible, i.e., the contact between the flexible surface and the rigid surface. First, we select two groove surfaces of the driving pulley as Surface and then select two flexible transmission surfaces as Patchset (i.e., chip set). Thus, the contact between the flexible surface and the rigid surface is generated. Then, we set the coefficient of elasticity between the cogged Vbelt and the driving pulley as $3000 \mathrm{~N} / \mathrm{mm}$ and the friction coefficient as 0.5 . In addition, we add a contact between the flexible surface and the rigid surface between the cogged V-belt and the driven pulley. The contact parameters are the same as between the driving pulley and the cogged V-belt. The complete simulation model of the drive and contact is shown in figure 3 . The simulation model in figure 3 is a trapezoidal cogged V-belt, and the steps of the simulation model of the triangular and circular cogged V-belts are the same as those of the trapezoidal cogged V-belt (the details are omitted for brevity) [16-18].

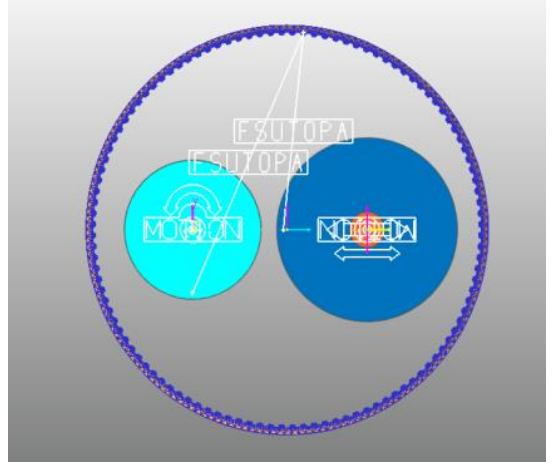

Figure 3. Simulation model of triangular cogged V-belt.

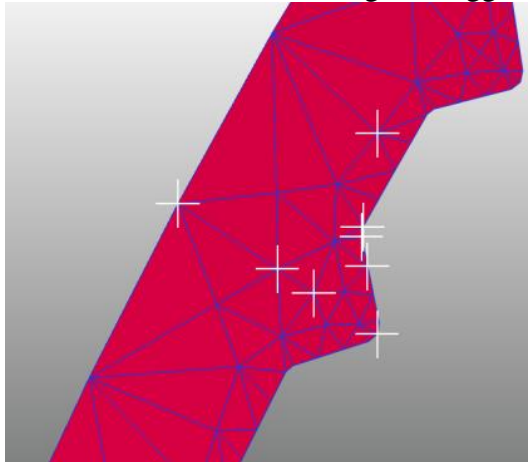

Figure 4. Output nodes

To study the change in the stress on the nodes with different positions, we select the output nodes at the root, 
back and back of the belt (figure 4). We set the simulation time as $0.6 \mathrm{~s}$ and the simulation step as 1000 .

\section{Results analysis}

\subsection{Simulation results for rigid flexible coupling of trapezoidal, circular and triangular cogged V- belts}

After the simulation, the equivalent stress nephogram of the cogged V-belt can be viewed by the Contour option. Under the condition that the driving pulley speed is 700 $\mathrm{r} / \mathrm{min}$, figure 5 shows the stress distribution of the trapezoidal cogged V-belt and the belt teeth. The AB segment is the tight side of the cogged V-belt, and the belt body generally withstands tight side pulling stress. The BC segment is a driven pulley segment whose bent follower is the driven pulley, and the belt body generally withstands bending stress and the frictional stress between the driven pulley and itself. The CD segment is the loose side of the cogged V-belt, and the belt body generally withstands loose side pulling stress. The stress of the DA segment is consistent with that of the BC segment. However, the small pulley is smaller in size, and the bending is more serious. Therefore, the bending stress is greater. As shown in figure 5, the maximum stress occurs at $0.0048 \mathrm{~s}$. At this moment, the driven pulley and the belt begin to come into contact with one another, the stress increases due to the collision, and the maximum stress value is $252 \mathrm{~N} / \mathrm{mm}^{2}$. Regarding the stress distribution of the circular cogged V-belt and the triangular cogged V-belt with the same method, the results indicate that the maximum stress of the circular cogged V-belt also occurs at $0.0048 \mathrm{~s}$. That is, when the driven pulley and the belt are in contact with one another and when the driven wheel starts, the maximum stress value at $0.0048 \mathrm{~s}$ is $315 \mathrm{~N} / \mathrm{mm}^{2}$. The maximum stress of the triangular cogged V-belt occurs at $0.169 \mathrm{~s}$. The animation shows that serious belt slipping occurs at 0.169 $\mathrm{s}$, with serious extrusion from the driven pulley part, which causes the bending stress to dramatically increase to a level far higher than that of the trapezoidal and circular cogged V-belts, whereby the maximum stress is $954 \mathrm{~N} / \mathrm{mm}^{2}$.

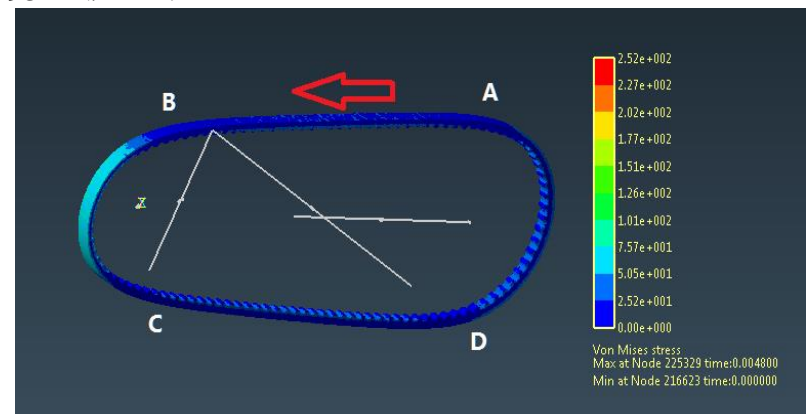

Figure 5. Stress distribution of triangular cogged-V belt

To analyse the influence of tooth form on the transverse vibration of the belt power transmission, the displacement curve and stress curve along the Y direction of the selected output node under different belt speed conditions is plotted. Under the condition that the driving pulley speed is $700 \mathrm{r} / \mathrm{min}$, figure 6 shows the displacement curve along the $\mathrm{Y}$ direction of the trapezoidal cogged V-belt back node, and figure 7 shows the stress curve of the trapezoidal cogged V-belt node. In figure 6 , the maximum stress occurs at the moment that the node moves to the driving pulley. Because the radius of the driving pulley is smaller, the belt withstands a greater bending stress. When the node moves to the tight side and the loose side, the tensile stress is smaller, and the stress on the tight side is approximately the same as on the loose side. When the driven pulley is large, the stress value is close to the tight side and the loose side, and both are less than the stress at the moment that the node moves to the small pulley. In figure 7, the 235740 value is for the back node of the tooth, 235735 is for the root node, and 229096 is for the back node. Combining the form feature of the trapezoidal cogged V-belt and figure 7 , it is found that the stress at the root node is the largest, followed by the stress at the back node of the tooth, and then the stress at the back node. This outcome shows that the stress concentration occurs at the root of the tooth, and the choice of proper fillet radius can reduce the influence of stress concentration.

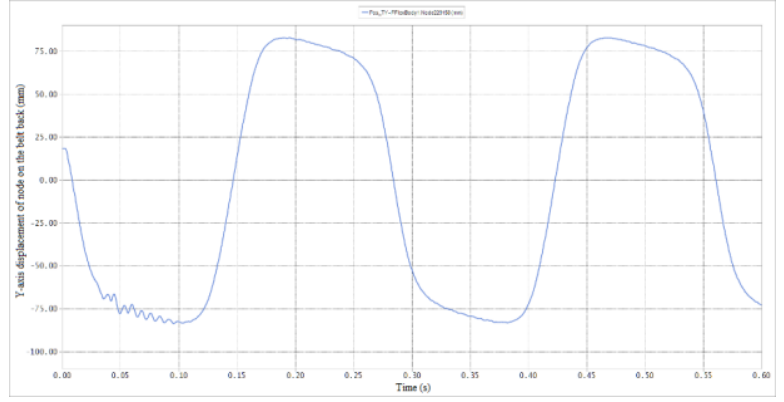

Figure 6. $\mathrm{Y}$-axis displacement curve of node on the belt back at $700 \mathrm{r} / \mathrm{min}$.

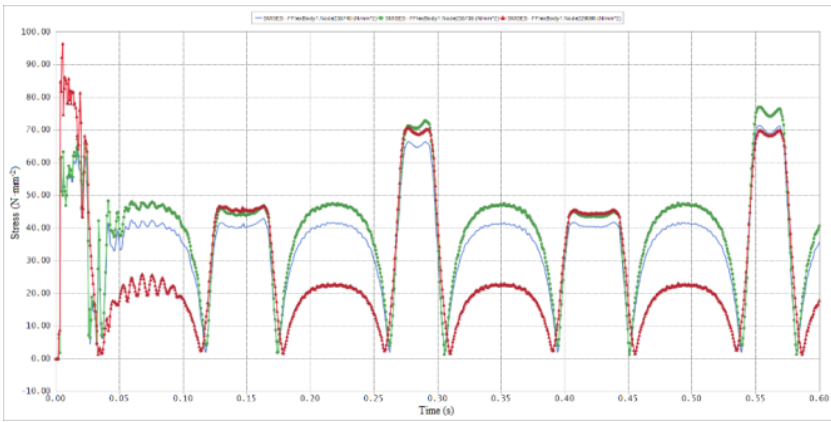

Figure 7. Stress curve of nodes at $700 \mathrm{r} / \mathrm{min}$.

Under other belt speed conditions, the simulation results for the trapezoidal, circular and triangular cogged V-belts are similar to the previously described results. Thus, they are omitted for brevity. The data are shown in table 5, 6 and 7. The transverse vibration displacement of three cogged V-belts varies with the speed (figure 8). The maximum bending stress of the root node varies with the speed (figure 9).

\subsection{Tooth form contrast conclusion}

When three types of cogged V-belt are compared according to $700 \mathrm{r} / \mathrm{min}$ stress distribution nephogram results, the maximum stress of the trapezoidal cogged Vbelt is $252 \mathrm{~N} / \mathrm{mm}^{2}$, that of the circular cogged V-belt is 
$315 \mathrm{~N} / \mathrm{mm}^{2}$, and that of the triangular cogged V-belt is $954 \mathrm{~N} / \mathrm{mm}^{2}$. These results indicate that the maximum stress of the trapezoidal cogged V-belt is the lowest. Compared with the vibration at $700 \mathrm{r} / \mathrm{min}$, the vibration of the trapezoidal cogged V-belt and the circular cogged $\mathrm{V}$-belt are mostly consistent in the transmission process, and the amplitude is smaller. In contrast, the triangular cogged V-belt vibration is violent, and the slip is serious. The maximum bending stress of the trapezoidal cogged $\mathrm{V}$-belt is $78 \mathrm{~N} / \mathrm{mm}^{2}$, that of the circular cogged V-belt is $98 \mathrm{~N} / \mathrm{mm}^{2}$, and that of the triangular cogged V-belt is 425 $\mathrm{N} / \mathrm{mm}^{2}$. These outcomes indicate that the trapezoidal cogged V-belt has the least bending stress. Similarly, the vibration and stress of the different tooth forms at low speed and high speed can be compared. A comprehensive comparison reveals that at various speeds the maximum transverse vibration of the trapezoidal cogged V-belt is smaller, the vibration is relatively stable with a smaller increase, and the maximum bending stress is smaller and increases slightly with increasing speed. The vibration of the circular cogged V-belt is consistent with the trapezoidal cogged V-belt at low speed. However, the maximum transverse vibration first increases and then decreases with increasing speed, the vibration is unstable, the maximum bending stress first increases and then decreases with increasing speed, and the increase and decrease are higher. The maximum transverse vibration and maximum bending stress of the triangular cogged $\mathrm{V}$ belt decrease with the increase in the speed, which shows that the triangular cogged V-belt is more suitable for high-speed belt power transmission. The comprehensive analysis shows that the overall transmission performance of the trapezoidal cogged V-belt is better than that of the circular and triangular cogged $\mathrm{V}$-belts. When choosing or designing a cogged V-belt, the trapezoidal cogged V-belt format is preferable.

Table 5. Simulation results for trapezoidal cogged V-belt at various speeds.

\begin{tabular}{|c|c|c|c|c|c|}
\hline & $700 \mathrm{r} / \mathrm{min}$ & $1225 \mathrm{r} / \mathrm{min}$ & $1750 \mathrm{r} / \mathrm{min}$ & $2275 \mathrm{r} / \mathrm{min}$ & $2800 \mathrm{r} / \mathrm{min}$ \\
\hline Maximum amplitude (mm) & 5 & 28 & 37 & 40 & 50 \\
\hline Maximum bending stress at the back node of a tooth $\left(\mathrm{N} / \mathrm{mm}^{2}\right)$ & 72 & 66 & 60 & 50 & 74 \\
\hline Maximum bending stress at the root node $\left(\mathrm{N} / \mathrm{mm}^{2}\right)$ & 78 & 90 & 89 & 91 & 115 \\
\hline Maximum bending stress at the back node $\left(\mathrm{N} / \mathrm{mm}^{2}\right)$ & 72 & 74 & 74 & 80 & 83 \\
\hline Maximum transverse vibration displacement (mm) & 83.68 & 90.25 & 96.17 & 96.2 & 108.61 \\
\hline
\end{tabular}

Table 6. Simulation results for circular cogged V-belt at various speeds.

\begin{tabular}{|c|c|c|c|c|c|}
\hline & $700 \mathrm{r} / \mathrm{min}$ & $1225 \mathrm{r} / \mathrm{min}$ & $1750 \mathrm{r} / \mathrm{min}$ & $2275 \mathrm{r} / \mathrm{min}$ & $2800 \mathrm{r} / \mathrm{min}$ \\
\hline Maximum amplitude (mm) & 5 & 66.11 & 49.77 & 44.33 & 50 \\
\hline Maximum bending stress at the back node of a tooth $\left(\mathrm{N} / \mathrm{mm}^{2}\right)$ & 33 & 193.28 & 476.41 & 80.38 & 93.01 \\
\hline Maximum bending stress at the root node $\left(\mathrm{N} / \mathrm{mm}^{2}\right)$ & 98.05 & 206.92 & 539.66 & 121.71 & 147.21 \\
\hline Maximum bending stress at the back node $\left(\mathrm{N} / \mathrm{mm}^{2}\right)$ & 68 & 120.17 & 252.87 & 94.14 & 84.86 \\
\hline Maximum transverse vibration displacement (mm) & 83.31 & 124.3 & 109.4 & 107.08 & 109.44 \\
\hline
\end{tabular}

Table 7. Simulation results for triangular cogged V-belt at various speeds.

\begin{tabular}{cccccc}
\hline & $700 \mathrm{r} / \mathrm{min}$ & $1225 \mathrm{r} / \mathrm{min}$ & $1750 \mathrm{r} / \mathrm{min}$ & $2275 \mathrm{r} / \mathrm{min}$ & $2800 \mathrm{r} / \mathrm{min}$ \\
\hline Maximum amplitude $(\mathrm{mm})$ & 70 & 68.84 & 41.91 & 63.55 & 100 \\
Maximum bending stress at the back node of a tooth $\left(\mathrm{N} / \mathrm{mm}^{2}\right)$ & 425 & 261.43 & 367.09 & 404.84 & 105.41 \\
Maximum bending stress at the root node $\left(\mathrm{N} / \mathrm{mm}^{2}\right)$ & 426.74 & 283 & 543.17 & 566.67 & 135.57 \\
Maximum bending stress at the back node $\left(\mathrm{N} / \mathrm{mm}^{2}\right)$ & 245 & 227.78 & 311.60 & 302.02 & 127 \\
Maximum transverse vibration displacement $(\mathrm{mm})$ & 129.02 & 135.2 & 128 & 116.18 & 111.05 \\
\hline
\end{tabular}

\subsection{Belt speed contrast conclusion}

When figure 8 and 9 are combined, it is found that the belt speed has different influences on the various tooth forms. For the trapezoidal cogged V-belt, the transverse vibration becomes more severe with the increase in the speed. However, the increase is not obvious, and the maximum bending stress of the root node slightly increases with the increase in the speed. For the circular cogged V-belt, the vibration first increases and then decreases with the increasing speed, which shows that this belt is not suitable for operation under the condition of $1225 \mathrm{r} / \mathrm{min}$ speed. For this belt, the maximum bending stress of the root node first increases and then decreases at the speed of $1225 \mathrm{r} / \mathrm{min}-2275 \mathrm{r} / \mathrm{min}$ and reaches a maximum value at $1750 \mathrm{r} / \mathrm{min}$. For the triangular cogged V-belt, vibration decreases with the increase in speed, which shows that this belt is not suitable for operation at a low speed. For this belt, the maximum bending stress of the root node is larger at low speed and decreases significantly at a high speed to a value close to the values of the other two cogged V-belts. Therefore, when a trapezoidal cogged V-belt is selected as the transmission mechanism, to reduce vibration and prolong the belt's working life, the driving pulley should be at a low speed during the actual use of a stump grinder. In this way, the transverse vibration can be effectively lowered, and the working life can be prolonged. Simultaneously, the stability of the belt transmission can be improved. 


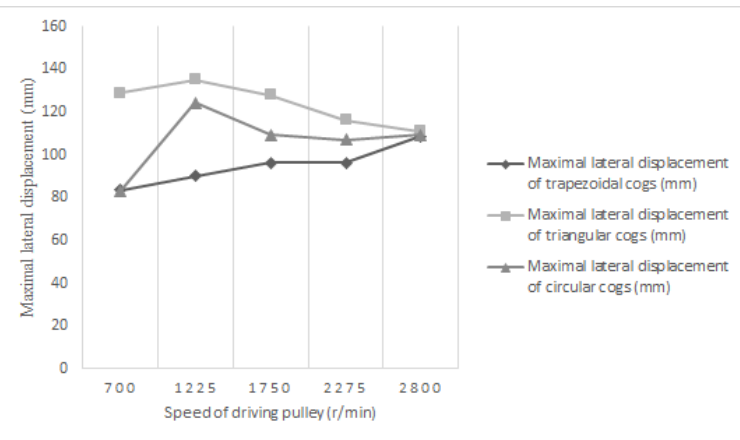

Figure 8. Maximal lateral displacement at various speeds.

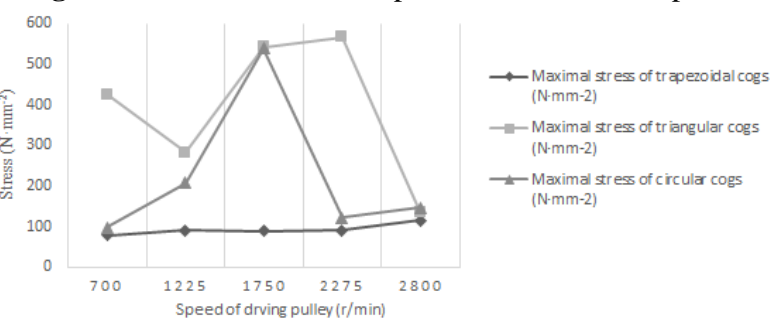

Figure 9. Maximal stress at different speeds.

\section{Conclusion}

In this paper, the virtual prototype simulation of cogged $\mathrm{V}$-belt power transmission was performed by finite element flexible body and rigid flexible coupling simulation, and the influence of tooth form and belt speed on the vibration and stress distribution of the cogged Vbelt was investigated.

First, 3D models of the belts, pulleys and cylinders were constructed using 3D software. Then, the models were imported into Recurdyn multi-body dynamics software to simulate rigid flexible coupling. After comparing and analysing the stress distributions, displacement curves and stress variation curves of trapezoidal, circular and triangular cogged V-belts under various belt speeds, it was found that tooth form affects the vibration and stress of the belt. The stability of the triangular cogged V-belt was the worst at the $700 \mathrm{r} / \mathrm{min}$ belt speed, and the maximum stress was $954 \mathrm{~N} / \mathrm{mm}^{2}$, which was much higher than that of the trapezoidal and circular cogged V-belts. This outcome means that the belt is not suitable for low-speed operation. For high-speed operation, the vibration of the three cogged V-belts was more consistent. However, the performance of the triangular cogged V-belt was poor, and the bending stress of the trapezoidal cogged V-belt was the lowest. When the simulation results for the three types of cogged $\mathrm{V}$ belts were compared for different speeds, it was found that the vibration and maximum stress of the trapezoidal cogged V-belt increased with increasing speed; those of the circular cogged V-belt first increased and then decreased; and those of the triangular cogged V-belt decreased with increasing speed. However, all of the data for the circular and triangular cogged V-belts were larger than those of the trapezoidal cogged V-belt. In a comprehensive consideration, the trapezoidal cogged Vbelt should be preferred in the design or selection of the tooth form because its comprehensive performance is better than that of the circular and the triangular cogged
V-belts. Additionally, the speed of the stump grinder cutting transmission system should be maintained at a low rate during actual operation to reduce lateral vibration, improve transmission stability and prolong the belt's working life.

\section{Acknowledgments}

First and foremost, I appreciate my college which gives me a comfortable learning atmosphere. Second, I would like to show my deepest gratitude to my tutor, Mr. Kan, who has walked me through all the stages of the writing of this thesis. Without his illuminating instruction and patience, this thesis could not have reached its present form. I am also greatly indebted to all my teachers who have helped me to develop the fundamental and essential academic competence. My sincere appreciation also goes to all my classmates, who are my proud of my life. Last but not least, I want to thank all my friends for their encouragement and support.

\section{References}

1. Jinwen Liu and Haixia Liu 2007 China Rubber/Plastics Technology and Equipment 33(10) 34-8

2. Zhanguo Li, Yaochen Shi, Shu'an Qin and et al 2012 Journal of Mechanical Transmission $\quad$ 36(09) 25-7

3. Yan Li, Zhanguo Li and Yaochen Shi 2014 Journal of Changchun University 24(02) 156-9

4. Zhanguo Li, Hao Li, Yaochen Shi and et al 2015 Journal of Changchun University 25(04) 9-12

5. Jianhua Guo, Qingxin Meng, Xin Yu and et al 2015 International Conference on Mechatronics, Electronic, Industrial and Control Engineering (Atlantis Press)

6. Dong Jiao, Zhenghao Ge, Tongyang Zhang and et al 2014 Journal of Mechanical Transmission 71-3

7. G L Zhou and S S Hao 2009 Materials Science Forum 628-9; 61-6

8. Y Chen and H Xue 2010 International Conference on Intelligent System Design and Engineering Application (IEEE Computer Society) pp 949-51

9. Zhanguo Li, Yunhe Zhang and Yaochen Shi 2013 Journal of Mechanical Transmission 37(08) 34-6

10. Kang Yuan, Qunfeng Fu and Guoxiang Huang 2015 Journal of Mechanical Transmission 39(07) 94-7

11. Tao Wang and Xiangyi Guan 2009 Science \& Technology Information 31 115-48

12. Dengyun Ma, Biao Xiong, Fantao Fang and et al 2014 Journal of Mechanical Transmission $\quad$ 38(09) 118-22

13. Zhenghao Ge, Kaikai Zhang, Jinsheng Liang and et al 2011 Journal of Mechanical Transmission 35(03) 64-6

14. Yuandong Liu, Wenlin Wang and Mingjun Luo 2013 Journal of Mechanical Transmission $\quad 37(06) \quad 28-$ 32 
15. Yi Liu 2013 Application and improvement of multi body dynamics simulation based on Recurdyn (Beijing: Publishing House of Electronics Industry)

16. Xiaolong Wang 2014 Optimization Design of Toothed Wrapping Narrow-V Belt and its Relevant Experimental Study (Harbin: Harbin Institude of Technology)
17. Yongbin Du 2011 Design and Reaearch of Banded Wedge and Synchronous $V$ Belt for Beam Pumping (Dongying: China University of Petroleum)

18. Zhanguo Li, Xiuguang Yang, Jinfang Wang and et al 2015 Journal of Mechanical Transmission 39(07) 154-7 